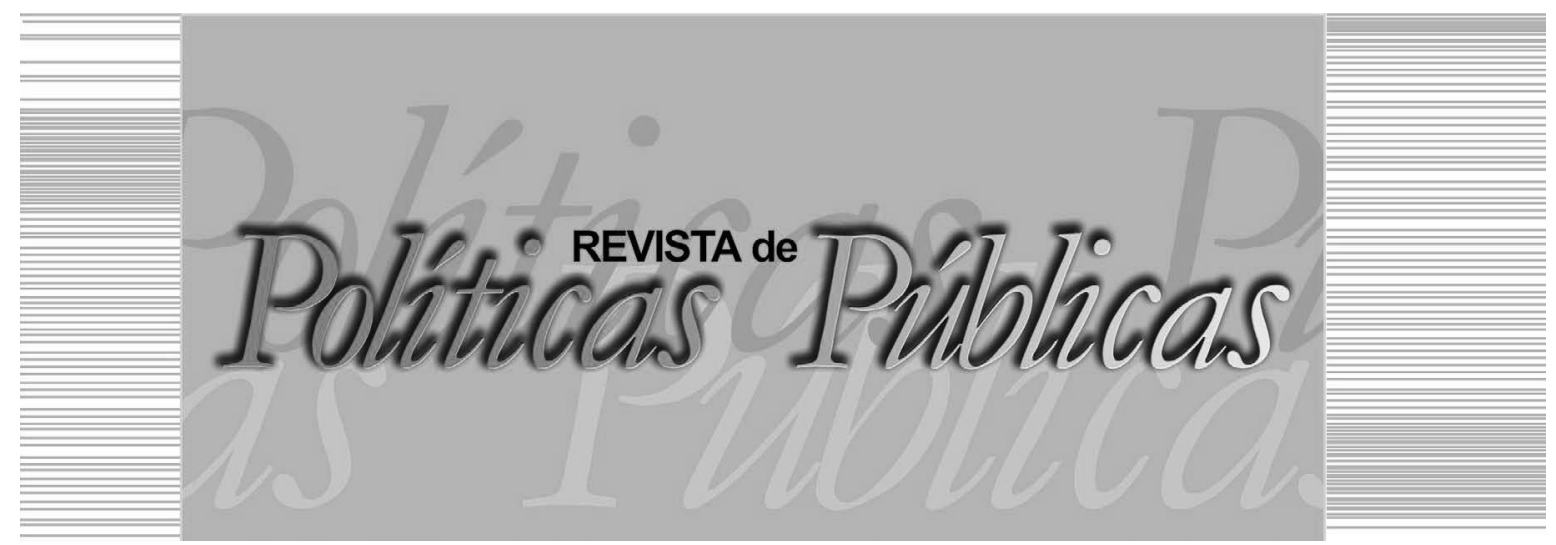

\title{
ANÁLISE COMPARADA DE POLITICAS PÚBLICAS PARA BICICLETA: Nova York, Cidade do México e São Paulo
}

\author{
Victor Callil \\ Daniela Constanzo de Assis Pereira ${ }^{2}$
}

\section{Resumo}

O artigo tem como objetivo entender os impactos das políticas de mobilidade, por bicicleta, em três grandes cidades: Nova York, Cidade do México e São Paulo. Para isso, apresenta as trajetórias dessas políticas e os instrumentos de política pública adotados em cada caso. Assim, analisa os resultados a partir de contagens de ciclistas em cada local e a redução de acidentes e mortes com ciclistas.

Palavras-chave: Mobilidade urbana, políticas públicas, bicicleta.

\section{A COMPARATIVE ANALYSIS OF PUBLIC POLICIES FOR \\ BICYCLE: New York, Mexico City and São Paulo}

\begin{abstract}
This text aims to examine the impact of mobility policies by bicycle in three big cities: New York, Mexico City and São Paulo. In order to do so, we present the public policies trajectories and their instruments in each case. The results were analyzed with cycling counts in each location and data of accident reduction with cyclists.

Key words: Urban mobility, public policies, bicycle.

\footnotetext{
Turismólogo, Mestre em Sociologia pela Universidade de São Paulo (USP), Pesquisador do Centro Brasileiro de Análise e Planejamento (CEBRAP). E-mail: vcallil87@gmail.com E-mail: danicosper@gmail.com / Centro Brasileiro de Análise e Planejamento - CEBRAP: R. Morgado de Mateus, 615, Vila Mariana, São Paulo - SP. CEP: 04015-051.
}

2 Cientista Socia., Doutoranda em Ciência Política pela USP, Pesquisadora do CEBRAP.
\end{abstract}




\section{INTRODUÇÃO}

Este artigo colabora para a análise do impacto de políticas públicas de mobilidade, por bicicleta, a partir da comparação de três casos escolhidos por serem metrópoles, com grande circulação de pessoas, problemas de congestionamento e histórico recente de ações de incentivo ao uso da bicicleta como modal de transporte: Nova York, Cidade do México e São Paulo. Com isso, pretende-se colaborar para o avanço no entendimento sobre as diferentes estratégias de política pública e seus efeitos. Assim, buscou-se compreender o que as cidades fizeram, como, e quais resultados obtiveram.

Para isso, foram observados dados de instrumentos de políticas públicas nas cidades, como construção de ciclovias e ciclofaixas, políticas de traffic calming ${ }^{1}$, sistemas de bike sharing, organizações da sociedade civil, porcentagem de viagens por bicicleta, taxa de mortalidade de ciclistas e contagens de ciclistas.

$\mathrm{O}$ artigo se divide em três partes, além da introdução e conclusão. Na primeira, são apresentados os diferentes usos da bicicleta e sua emergência como um modal de transporte. Na segunda, são narradas as políticas públicas das cidades e alguns dados sobre a sua implantação. Por último, é feita uma análise do impacto destas políticas e são apresentadas as conclusões.

\section{ORIGEM DA BICICLETA COMO MEIO DE LOCOMOÇÃO}

Apesar de a bicicleta ganhar cada vez mais espaço no debate sobre mobilidade urbana (PUCHER et al., 2010; MIDGLEY, 2009; 2011; CERVERO, 2009; WANG, 2013), nem sempre ela serviu para esses fins; seu precursor, o velocípede, era um brinquedo da elite europeia no início dos anos 1800 , e a bicicleta, como conhecemos hoje, surgiu na segunda metade do sec. XIX como artigo de luxo. (COX, 2015). O primeiro boom de produção e venda de bicicletas no mundo ocidental se deu nos anos 1890, mas somente depois da década de 1920 ela começou a ser utilizada massivamente para deslocamento, principalmente nas cidades industriais por trabalhadores. (SMETHURST, 2015).

A acessibilidade econômica da bicicleta se deu, entre outros fatores, pelo aumento da oferta com o surgimento de novos produ- 
tores e derrubada de seu preço, resultado da complicada situação financeira enfrentada pela Europa no final da $1^{\text {a }}$ Guerra Mundial.

A década de 1950 marca o declínio na produção e uso da bicicleta, já que boa parte dos grandes centros urbanos europeus passou a investir em transporte de massa e redes de ônibus, enquanto a indústria automobilística, já consolidada no mundo, aumentava a produção e ampliava seu mercado para além das classes mais elitizadas. Outro aspecto importante é o crescimento das cidades e, com isso, o aumento das distâncias a serem percorridas. (COX, 2015).

Os malefícios do aumento de veículos motorizados nas grandes cidades já eram percebidos no final dos anos 1960. Goodyear (2011) coloca que os principais motivos que levaram países ocidentais como a Holanda, a investir em políticas cicloviárias a partir de 1970, foram o aumento do tráfego motorizado ocupando o espaço público, o número de vítimas fatais de acidentes de trânsito e a crise do petróleo, que causou aumento no preço dos combustíveis. Na mesma década, o consumo de bicicleta no mundo voltou a crescer novamente, associado ao uso recreativo. Exceção de países como Holanda, Dinamarca e Alemanha, cujas cidades figuram hoje entre aquelas com maior taxa de uso de bicicleta, sendo que entre 1975 e 1995 essa proporção saltou de $20 \%$ para $45 \%$ das viagens. (SHAHEEN; GUZMAN; ZHANG, 2010).

Em outros países ocidentais como Canadá e Estados Unidos, a bicicleta começou a entrar no debate público por volta dos anos 1990. As políticas e planos cicloviários, no entanto, se consolidaram somente nos anos 2000. Pucher e Buehler (2010) mostram que, apesar das políticas cicloviárias nas grandes cidades canadenses, sua taxa de uso atinge no máximo $2 \%$.

O plano estratégico de mobilidade do governo federal estadunidense (2013) para 2014 a 2018 destaca que a ampliação de deslocamentos de modo sustentável nas cidades está associada à melhoria na qualidade de vida dos residentes. Vantagens econômicas e ambientais do uso da bicicleta em relação ao carro também são levadas em consideração para justificar maior investimento em infraestrutura de mobilidade ativa.

A Comissão Nacional para o Uso Eficiente de Energia (2014) do governo federal mexicano aponta a bicicleta como alternativa para os meios urbanos em razão da sua independência em relação à 
rede elétrica e a combustíveis fósseis, além da gratuidade do recurso energético necessário para locomoção.

Em 2007, o governo brasileiro publicou o Caderno de Referências para Elaboração de Plano de Mobilidade por Bicicleta, no qual explica que por conta das curtas distâncias viajadas e da ausência de sistemas de transporte público, pequenas cidades do país possuem proporção maior de viagens de bicicleta do que as metrópoles, apontando que nas grandes cidades a bicicleta pode ser uma boa opção para ampliar as possibilidades de deslocamento dos cidadãos, desde que haja implantação de políticas cicloviárias. (BRASIL, 2007).

A partir dos anos 1990 e 2000 surgem nos Estados Unidos, México e Brasil documentos indicativos de que os governos federais desses países apoiam a inserção da bicicleta na matriz modal de suas cidades. Por outro lado, o tamanho dessas cidades e a necessidade de transportar um volume muito grande de pessoas fazem da viabilização da bicicleta um desafio. Surgem então os questionamentos que guiam este texto: essas cidades incorporaram políticas de incentivo à bicicleta na sua trajetória recente? Se sim, quais? Essas políticas se assemelham entre si? É possível mensurar os impactos dessas políticas?

\section{- Nova York}

A matriz de transportes urbanos da cidade de Nova York conta com uma extensa rede de metrô, Bus Rapid Transit (BRTs), ônibus, balsas, táxis e sistema de bike sharing. Mesmo assim, é difícil deslocar a população de 8,5 milhões de habitantes. O metrô é o transporte público mais utilizado com $44 \%$ das viagens a trabalho; depois vem o automóvel, com $23 \%$ e de ônibus com $13 \%$.

Embora organizações da sociedade civil como a Transportation Alternatives e Bike New York existam desde os anos 1970, a cidade tinha poucas ações de segurança para ciclista até a década de 1990. Isso começou a mudar a partir das gestões municipais da década de 2000. O número de ciclovias e ciclofaixas entre os anos de 1996 e 2009 foi de $190 \mathrm{~km}$ para $900 \mathrm{~km}$. (PUCHER; KAMANOFF; SCHIMER, 1999; PUCHER et al., 2010). Até setembro de 2015, a cidade já tinha mais de $1.500 \mathrm{~km}$ de vias segregadas para circulação de ciclistas. A bicicleta passou a integrar de maneira mais sólida o planejamento de transporte nova-iorquino na gestão do republica- 
no Michael Bloomberg (2002-2013), com o Plano Nova York 2030 (NYC 2030) (UNITED STATES, 2007). Com o objetivo de preparar a cidade para o crescimento de 1 milhão de habitantes, estimado para 2030, o projeto prevê melhorias em diversas áreas, privilegiando mecanismos sustentáveis de modificação e uso do espaço urbano.

A partir do NYC 2030, o Departamento de Transportes (Departament of Transportation - DOT) da cidade norte-americana, chefiado na época por Janette Sadik-Khan (2007-2013), elaborou um plano cicloviário de cerca de 3 mil $\mathrm{km}$ conectando diversas áreas da cidade. A implementação de sistema de bike sharing também foi levantada pelo plano. Como parte do projeto NYC 2030, bicicletários e paraciclos foram implementados na cidade; em 1996 Nova York contava com 600 paraciclos, em 2009 esse número chegou a mais de 6 mil. Isso foi possível, principalmente, por meio de um plano de expansão promovido pelo DOT, chamado CityRack, que entrou em vigor a partir de 2006. Pucher e outros (2010) ressalta, entretanto, que o aumento da oferta de locais para estacionar bicicletas na cidade se deu com a mudança da legislação, em 2009, que passou a obrigar uma cota mínima de locais apropriados para o travamento de bicicletas em edificações residenciais e comerciais.

Em maio de 2013, último ano da gestão Bloomberg, foi lançado o Citi Bike, sistema de compartilhamento de bicicletas nova-iorquino, com cerca de 500 estações na ilha de Manhattan, nos bairros do Queens e Brooklyn e na cidade de Jersey City.

Em 2014, o democrata Bill de Blasio assumiu a prefeitura de Nova York. Embora o DOT continue planejando e implementando novos trechos de ciclovia do plano consolidado em 2007 (UNITED STATES, 2007), sua política principal em relação ao tráfego é o Vision Zero, que parte do pressuposto de que não há taxa de mortalidade aceitável para o trânsito de uma cidade (Quadro 1). Os principais eixos de ação são: diálogo com a população, endurecimento na aplicação das leis de trânsito, design das ruas e mudanças na legislação. O programa tem apresentado resultados positivos, já que entre 2013 e 2016 as mortes de pedestres diminuíram em 21\%. (UNITED STATES, 2017d).

Mesmo tendo como alvo principal a redução do número de pedestres atropelados, as ações da prefeitura beneficiam também os ciclistas, pois tornam as ruas mais seguras para quem está fora de veículos motorizados. As principais diretrizes adotadas pelo DOT 
para escolher as ruas a serem tranquilizadas são áreas próximas a escolas e regiões com muitos idosos. Os principais dispositivos utilizados são a redução das velocidades máximas permitidas, estreitamento das faixas, transformação de faixas de rolamento em áreas de convivência para pedestres, ampliação das calçadas nos locais de travessia, implementação de obstáculos para reduzir a velocidade e barreiras de proteção entre a rua e o passeio e travessias elevadas. (UNITED STATES, 2016).

Quadro 1 - Políticas para bicicleta em Nova York

\begin{tabular}{|c|c|c|}
\hline Projeto & Ano de início & Ação \\
\hline Citi Rack & 2006 & Instação de paraciclos \\
\hline NYC2030 & 2007 & $\begin{array}{c}\text { Implemtação de ciclovias e } \\
\text { ciclofaixas }\end{array}$ \\
\hline Lei Municipal & 2009 & $\begin{array}{c}\text { Aprovação de lei que obriga os } \\
\text { estabelecimentos públicos e privados } \\
\text { ofertarem vagas para travar } \\
\text { bicicleta dentro de seus } \\
\text { estacionamentos }\end{array}$ \\
\hline Citi Bike & 2013 & Sistema de bicicletas compartilhadas \\
\hline Vision Zero & 2014 & Políticas de traffic calming \\
\hline Fonte: Elaboraça própria
\end{tabular}

Atualmente, alguns problemas ainda são agravantes para os ciclistas da cidade. Muitas das ciclovias mais antigas, no centro da cidade, são excessivamente estreitas e a chance de acidentes é alta, pois boa parte delas é feita junto aos carros estacionados, coladas ao meio fio (porta do passageiro) ou da via de rolamento (porta do motorista) com frequente invasão das ciclovias por motoristas e pedestres (TUCKEL; MILCZARSKI, 2009). Outra questão é a falta de integração da bicicleta com os transportes públicos, sendo proibido entrar com a bicicleta nos ônibus. Nas estações de metrô o acesso com a bicicleta é permitido 24 horas por dia, todos os dias (UNITED STATES, 2016), entretanto, por serem antigas, as estações não atendem a parâmetros de acessibilidade, sem rampas de acesso ou elevadores. Além disso, não possuem bicicletários e nas ruas do entorno não há paraciclos. Por isso, em alguns locais, os arredores das estações ficam cheios de bicicletas presas em postes de iluminação e na grade que separa o passeio da rua. (PUCHER et al., 2010).

Mesmo assim, as ações desenvolvidas em Nova York nos últimos 15 anos em favor de ciclistas e pedestres surtiram 
ANALISE COMPARATIVA DE POLÍtiCAS PÚBLICAS PARA BICICLETA EM TRÊS GRANDES CIDADES: Nova York, Cidade do México e São Paulo

efeitos. Entre 2005 e 2015 o número de viagens diárias de bicicleta aumentou em média $10 \%$ ao ano (Tabela 1 ). O número de mortes de ciclistas permaneceu relativamente estável. Ou seja, ao analisar os dados ao longo do tempo, viagens crescem, mortes não (Gráfico 1).

Tabela 1 - Acidentes e viagens em Nova York (2005-2015)

\begin{tabular}{|c|c|c|c|}
\hline Ano & $\begin{array}{c}\text { Mortes de } \\
\text { ciclistas no ano }\end{array}$ & $\begin{array}{c}\text { Viagens de bicicleta } \\
\text { por dia (mil) }\end{array}$ & $\begin{array}{c}\text { Morte / Nתmero } \\
\text { de viagens }\end{array}$ \\
\hline 2005 & 22 & 170 & 0,13 \\
\hline 2006 & 18 & 180 & 0,10 \\
\hline 2007 & 24 & 210 & 0,11 \\
\hline 2008 & 22 & 240 & 0,09 \\
\hline 2009 & 12 & 240 & 0,05 \\
\hline 2010 & 19 & 250 & 0,08 \\
\hline 2011 & 22 & 270 & 0,08 \\
\hline 2012 & 18 & 320 & 0,06 \\
\hline 2013 & 12 & 380 & 0,03 \\
\hline 2014 & 20 & 420 & 0,05 \\
\hline 2015 & 14 & 450 & 0,03 \\
\hline
\end{tabular}

Fonte: UNITED STATES. Department df Transportation. Cycling in the New York City: Cycling Trends in NYC. Nova York, 2017c.

Gráfico 1 - Viagens e acidente/viagens (2005-2015)

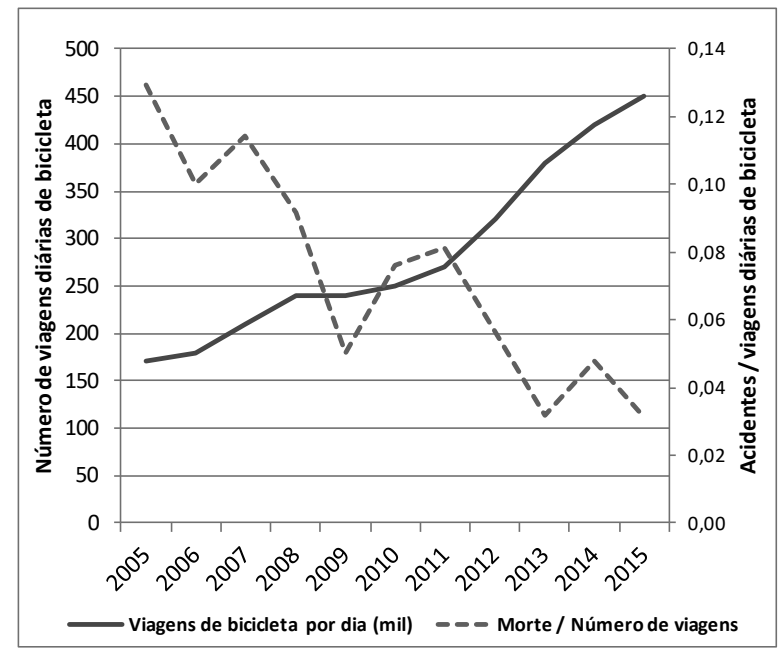

Fonte: (UNITED STATES, 2017c). 
As prioridades das políticas de transportes municipais se inverteram em Nova York a partir dos anos 2000. Se até os anos 1990 os ciclistas eram vistos como um elemento indesejável no tráfego (PUCHER; KAMANOFF; SCHIMER, 1999), atualmente o DOT possui muitas ações no sentido de aumentar a participação das bicicletas em sua matriz modal.

\section{- Cidade do México}

A Zona Metropolitana del Valle de México (ZMVM) está entre as maiores regiões metropolitanas do mundo, com 22 milhões de habitantes. Ela abriga a Cidade do México e mais 60 cidades. Milhões de viagens são realizadas diariamente na ZMVM, em sua maioria, por transporte público. No entanto, a maior parte das viagens é feita em modais de baixa capacidade, como os ônibus e micro-ônibus (que no Gráfico 2 incluem Camión, taxi, combi o colectivo $)^{2}$, além do automóvel com um quarto das viagens.

Gráfico 2 - Distribuição percentual de trechos de viagem por modo de transporte da população de 12 anos ou mais, e empregada

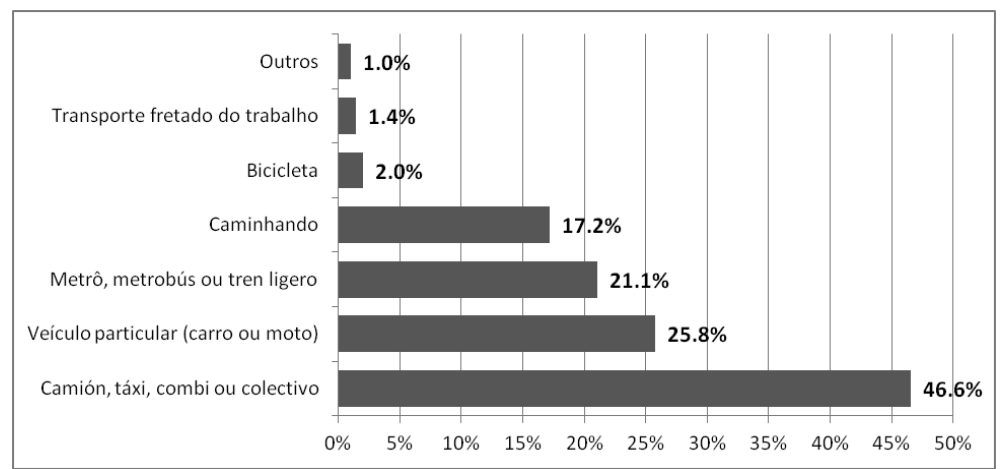

Fonte: INSTITUTO NACIONAL DE ESTADÍSTICA GEOGRAFÍA E INFORMÁTICA. Encuesta Intersensal 2015. Cidade do México, 2015.

As políticas cicloviárias na região tiveram como marco inicial o ano de 2002, quando o Governo do Distrito Federal (GDF), sob a gestão de Andrés Manuel Obrador, (Partido de la Revolución Democrática - PRD, 2001-2005), incluiu a construção de infraestrutura para bicicletas no Programa Integral de Transporte y Vialidad 20012006, primeira vez que a bicicleta entra em planos de mobilidade no país. (MÉXICO, 2002). Em 2003, uma das ciclovias previstas 
no plano começou a ser construída como medida compensatória do dano ambiental causado por uma via expressa construída na cidade, o Distribuidor Vial San Antonio. Tal ciclovia passa por diversas delegações da cidade ao longo de $60 \mathrm{~km}$.

A partir de 2004, medidas de incentivo ao uso da bicicleta foram adotadas pelo GDF, todas ligadas a programas ambientais em coordenação com a secretaria de mobilidade. A primeira delas foi o Programa de Educación Ambiental Itinerante, que era voltado para cultura e conscientização sobre uso da bicicleta na cidade. Dentro deste programa foram realizados debates e passeios com cicloativistas, além da implantação de 39 bicicletários ao longo da ciclovia, entre 2004 e 2006, e da permissão do ingresso de bicicletas no metrô aos domingos.

As políticas para mobilidade por bicicleta se intensificaram em 2007, na gestão de Marcelo Ebrard (PRD, 2007-2012) quando o Plan Verde de la Ciudad de México foi lançado. O principal objetivo do plano era definir uma rota para o desenvolvimento sustentável da cidade. Uma das estratégias para isso foi a promoção da cultura do uso da bicicleta com fins recreativos e de meio de transporte. Esse conjunto de medidas foi intitulado Estrategia de Movilidad en Bicicleta (EMB) (MÉXICO, 2017) e ainda está em funcionamento. Ele é ligado à Secretaria do Meio Ambiente (SMA) e conta com a participação da Universidad Nacional Autónoma de México (UNAM) e financiamento do Banco Mundial (BM). Os principais projetos implementados no plano estão listados no Quadro 2. Como pode ser observado, eles vão além da infraestrutura e incluem formação do ciclista, com o Biciescuela e promoção da cultura da bicicleta com passeios ciclísticos e ciclofaixas de lazer.

No ano de 2007 começou a ser implantado o Ecobici, sistema de compartilhamento de bicicletas da cidade. A primeira delegación escolhida para receber as estações foi Cuauhtémoc - centro financeiro da cidade -, que atrai $13,2 \%$ das viagens de bicicleta, das quais 45,5\% são para trabalho. (MEXICO, 2012). O sistema foi ampliado e está presente em mais duas delegaciones, Benito Juárez e Miguel Hidalgo. O Ecobici é administrado por uma empresa multinacional de publicidade, a Channel Outdoor. Hoje estão em funcionamento 452 estações e aproximadamente 6 mil bicicletas. O Ecobici foi implementado em conjunto com as demais políticas para bicicleta. Em todo o perímetro do sistema há sinalização vertical indicando Zona 
Ecobici, que pretende indicar para os motoristas que ali transitam ciclistas.

Quadro 2 - Políticas para bicicleta na Cidade do México

\begin{tabular}{|c|c|c|}
\hline Projeto & Ano de início & Ação \\
\hline $\begin{array}{c}\text { Ciclovía de la Ciudad de } \\
\text { México }\end{array}$ & 2003 & Ciclovia \\
\hline $\begin{array}{c}\text { Programa de Educacion } \\
\text { Ambiental Itinerante }\end{array}$ & 2004 & $\begin{array}{c}\text { Debates, passeios com cicloativistas, } \\
\text { bicicletários e bicicleta no Metrô }\end{array}$ \\
\hline Muevete em Bici & 2007 & $\begin{array}{c}\text { Passeios ciclísticos dominicais com } \\
\text { criação de ciclofaixas de lazer em } \\
\text { algumas vias da cidade }\end{array}$ \\
\hline $\begin{array}{c}\text { Infraestructura y } \\
\text { Equipamiento }\end{array}$ & 2007 & $\begin{array}{c}\text { Ciclovias, bicicletários e zonas de } \\
\text { trânsito acalmado }\end{array}$ \\
\hline ECOBICl & 2007 & Sistema de bicicletas compartilhadas \\
\hline BiciEscuela & 2013 & $\begin{array}{c}\text { Programa de capacitação sobre leis } \\
\text { de circulação da bicicleta dentro da } \\
\text { cidade, manutenção de bicicletas, } \\
\text { dentre outras coisas }\end{array}$ \\
\hline $\begin{array}{c}\text { bici estacionamiento } \\
\text { masivo em Pantitlán }\end{array}$ & 2014 & $\begin{array}{c}\text { Bicicletário público no centro de } \\
\text { transferência modal (CETRAM) } \\
\text { Pantitlán com aproximadamente } 400 \\
\text { vagas, com banheiro e oficina }\end{array}$ \\
\hline
\end{tabular}

Fonte: MÉXICO. Secretaria del Medio Ambiente del Distrito Federal. Movilidad Sustentable. Ciudad do México, 2017.

Ao mesmo tempo em que eram implantadas as políticas para bicicleta, cresciam os movimentos sociais de apoio a elas, e o principal é o Bicitekas, que existe desde 1998 e pressiona os governos do Distrito Federal desde a implementação da primeira ciclovia, em 2003. Em 2013, com o fim da gestão Ebrard, o movimento, em conjunto com outras organizações, lançou o manifesto Balance y lecciones aprendidas 2007-2012 no qual destaca as ações dessa gestão e expressa a importância da continuidade dessas políticas na próxima. (BICITEKAS, 2013).

Todas as políticas descritas acima foram coordenadas ou tiveram grande participação da SMA. Durante todo o período de implementação dessas políticas, o partido que governou a Cidade do México permaneceu o mesmo - PRD - o que facilitou sua continuidade.

Com base nos dados disponíveis, é possível observar alguns resultados das políticas descritas. $\mathrm{O}$ volume de ciclistas na ciclovia de uma das principais avenidas da cidade, Paseo de la Reforma, em um dia entre as 6:00 e as 22:00 aumenta a cada ano entre 2008 e 2013, mas seu maior crescimento foi em 2010, quando foi inaugurada a ciclovia na avenida e o número de ciclistas aumentou 18 vezes em relação ao ano anterior (Gráfico 3). Mesmo não tendo os dados 
ANALISE COMPARATIVA DE POLÍTICAS PÚBLICAS PARA BICICLETA EM TRÊS GRANDES CIDADES: Nova York, Cidade do México e São Paulo

para outros locais, 4.339 ciclistas em uma das avenidas da cidade é significativo, se comparado com contagens de outras cidades ${ }^{3}$. No mesmo período as viagens do Ecobici também cresceram. (ECOBICI, 2017).

Gráfico 3 - Contagem de ciclistas na Av. Paseo de La Reforma

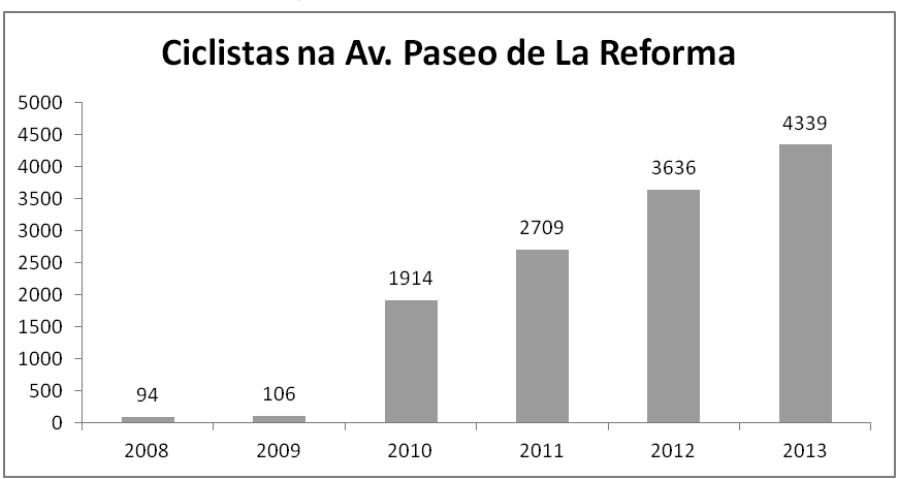

Fonte: INSTITUTO DE POLÍTICAS PARA EL TRANSPORTE Y EL DESARROLLO. Conteo ciclista: 2013. Cidade do México, 2014.

Sobre os acidentes com ciclistas, os dados mostram muita variação desde 2003 (Gráfico 4), com duas tendências mais claras; uma de crescimento entre 2003 e 2005 e uma de queda entre 2012 e 2015. No entanto, entre os acidentes mais graves, com vítimas fatais, não são encontradas tendências de ascensão ou declínio.

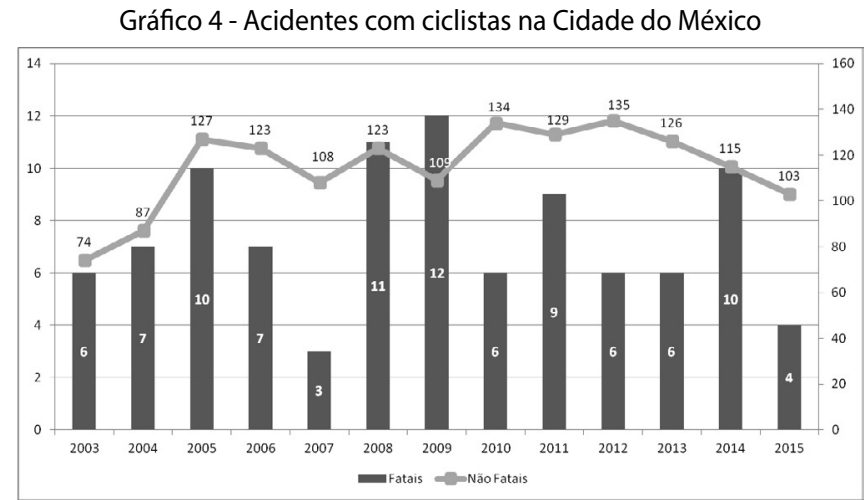

Fonte: INSTITUTO NACIONAL DE ESTADÍSTICA GEOGRAFÍA E INFORMÁTICA. Accidentes de tránsito terrestre en zonas urbanas y suburbanas. Ciudad de México, 2016. Disponível em:<http:// www.inegi.org.mx/est/lista_cubos/consulta.aspx?p=adm\&c=1>. Acesso em: 24 fev. 2017. 
Dentre as críticas feitas às políticas cicloviárias, estão a de que a infraestrutura implantada privilegia regiões da cidade onde há menos pessoas pedalando - a região central - e de que o Ecobici seria voltado para o turismo, também por conta da sua localização. (SANDOVAL, 2012; BICITEKAS, 2013). O manifesto do movimento Bicitekas, de 2013, afirma que $90 \%$ da infraestrutura ciclista da cidade está no centro, $5 \%$ na região norte e $5 \%$ na região sul da cidade.

\section{- São Paulo}

Na Região Metropolitana de São Paulo (RMSP) são realizadas diariamente 43 milhões de viagens (SÃO PAULO, 2013), das quais $29,5 \%$ são de modo principal automóvel e $36,5 \%$ por ônibus. A maior parte das viagens é no sentido periferia-centro de manhã, e no sentido contrário à tarde. Na cidade de São Paulo, a maior parte dos deslocamentos é feita por veículo de baixa capacidade - ônibus ou carro - e por conta disso as vias são congestionadas e o tempo de viagem alto. Segundo a pesquisa Origem e Destino, as viagens por modo principal bicicleta na cidade correspondiam, em 2007, a $0,6 \%$ do total (Gráfico 5).

Gráfico 5 - Viagens por modo principal bicicleta na RMSP

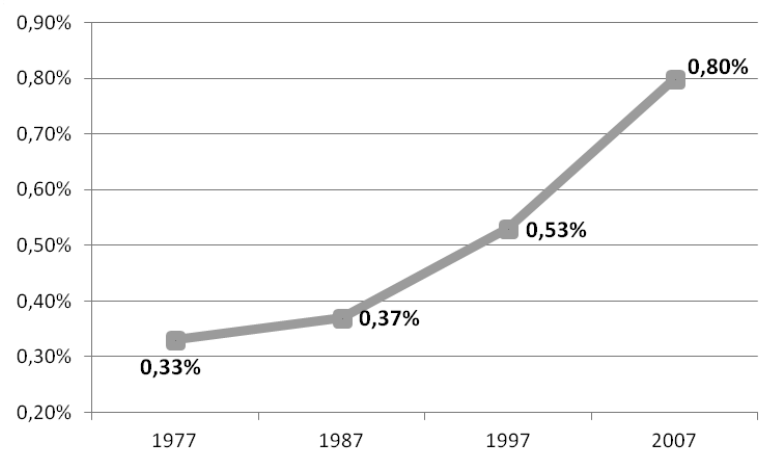

Fonte: SÃO PAULO. Secretaria de Estado dos Transportes Metropolitanos. Companhia do Metropolitano de São Paulo. Pesquisa Origem e Destino - 2007: síntese das informações - pesquisa domiciliar. São Paulo, 2008.

Desde o início dos anos 1990 até o começo dos 2000, algumas ações voltadas para bicicleta foram implantadas em São Paulo, mas todas dispersas, sem integrar um plano de mobilidade e quase 
todas voltadas para o lazer. (MALATESTA, 2014). As ações voltadas para bicicleta como meio de transporte começaram a ser implantadas mais sistematicamente em 2011, no governo Kassab (DEM, 2009-2012), quando a Secretaria Municipal de Transportes, Lazer e Recreação elaborou as Ciclorrotas com o objetivo de mapear rotas mais amigáveis para o ciclista, considerando os tipos de vias, o relevo da cidade e pontos de interesse, como equipamentos culturais e faculdades. Em 2013, elas foram atualizadas e ampliadas para mais regiões da cidade. Ainda em 2011, as ciclofaixas de lazer, que antes funcionavam em rotas de parques, foram ampliadas para diversos pontos da cidade, funcionando todos os domingos e feriados das $7 \mathrm{~h}$ às $16 \mathrm{~h}$.

Em 2012 começou a ser implantado o Bike Sampa, primeiro sistema de compartilhamento de bicicletas da cidade. Inicialmente localizado em um bairro residencial, a Vila Mariana, em 2013 o sistema foi expandido para outros distritos do centro, e em 2014, para as regiões central e leste da cidade. O sistema é financiado pelo Banco Itaú, mas sua utilização é pública. Outro sistema, com menor número de estações, foi implementado em 2013, o Ciclo Sampa, também de utilização pública, financiado pelo Banco Bradesco, localizado nos bairros dos Jardins, Itaim Bibi e Vila Madalena.

As políticas para bicicleta se intensificaram a partir de 2013, na gestão de Fernando Haddad (PT, 2013-2016). Nesse período, foi criado o Departamento de Planejamento, Estudos e Projetos Cicloviários (DLC) dentro da Companhia de Engenharia de Tráfego (CET) da Prefeitura da São Paulo e foi lançado, em 2014, o programa Ciclovia SP 400, responsável pela implantação de cerca de $400 \mathrm{~km}$ de ciclovias e ciclofaixas na cidade. Outras ações de incentivo e apoio à mobilidade por bicicleta também foram implementadas, como a construção de bicicletários públicos e a instalação de paraciclos, a redução da velocidade máxima permitida em diversas vias da cidade (incluindo as Áreas 40: regiões com velocidade máxima permitida de $40 \mathrm{~km} / \mathrm{h}$ ).

A gestão de João Dória Jr. (PSDB, 2017-2020), ainda em seu primeiro ano, implantou algumas ações relativas à mobilidade na cidade, como o aumento das velocidades nas marginais, vias expressas que tiveram redução de velocidades na gestão anterior. Em relação à mobilidade por bicicleta, foi instalado um bicicletário público no bairro do Paraíso (Quadro 3). 
Victor Callil | Daniela Constanzo de Assis Pereira

Quadro 3 - Políticas para bicicleta em São Paulo

\begin{tabular}{|c|c|c|}
\hline Projeto & Ano de início & Ação \\
\hline Ciclo Rotas & 2011 & $\begin{array}{c}\text { Mapeamento de rotas para ciclistas e } \\
\text { sinalização nas vias }\end{array}$ \\
\hline Ciclofaixas de lazer & 2011 & $\begin{array}{c}\text { Ampliamento das faixas e dos } \\
\text { horários de funcionamento }\end{array}$ \\
\hline Bike Sampa & 2012 & Sistema de bicicletas compartilhadas \\
\hline Ciclo Sampa & 2013 & Sistema de bicicletas compartilhadas \\
\hline Ciclovia SP 400 & 2014 & $\begin{array}{c}\text { Implementação de ciclovias e } \\
\text { ciclofaixas }\end{array}$ \\
\hline $\begin{array}{c}\text { Bicicletário Largo da } \\
\text { Batata }\end{array}$ & 2014 & $\begin{array}{c}\text { Bicicletário público próximo à estação } \\
\text { de metrô Faria Lima com 100 vagas }\end{array}$ \\
\hline $\begin{array}{c}\text { Bicicletário Praça dos } \\
\text { Arcos }\end{array}$ & 2015 & $\begin{array}{c}\text { Bicicletário público próximo à Avenida } \\
\text { Paulista com 47 vagas }\end{array}$ \\
\hline Bicicletário Paraíso & 2017 & $\begin{array}{c}\text { Bicicletário público próximo à estação } \\
\text { de metrô Paraíso com 52 vagas }\end{array}$ \\
\hline
\end{tabular}

Fonte: Elaboração própria.

Antes do início das políticas, os movimentos de ciclistas já se organizavam na cidade. O principal deles é o Ciclocidade (Associação dos Ciclistas Urbanos de São Paulo) que foi fundado em 2009, a partir da reunião de ativistas que atuavam na defesa da mobilidade por bicicleta. Nas eleições de 2012 e de 2016 a organização lançou rankings de prioridades para as políticas cicloviárias.

Com os dados disponibilizados pelo Ciclocidade e pelo Centro Brasileiro de Análise e Planejamento (CEBRAP), é possível observar uma tendência crescente de uso da bicicleta no período da implementação das políticas citadas acima, em várias vias da cidade (Gráfico 6).

Gráfico 6 - Contagens de ciclistas em vias de São Paulo

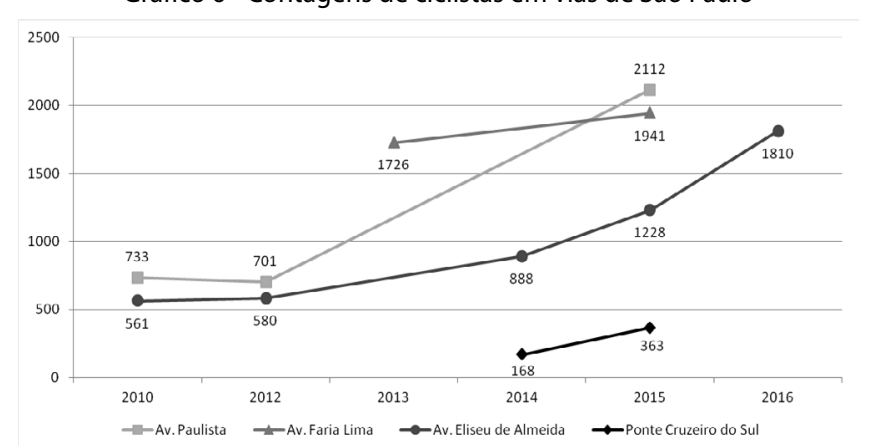


Fonte: Elaboração própria a partir dos dados: CICLOCIDADE. Contagens de ciclistas. São Paulo, 2017. Disponível em:<https://www.ciclocidade.org.br/contagem>. Acesso em: 28 nov. 2017; CENTRO BRASILEIRO DE ANÁLISE E PLANEJAMENTO. Contagem de ciclistas no município de São Paulo. São Paulo, 2015. Relatório técnico.

Os dados de acidentes com ciclistas mostram uma tendência decrescente desde 2005 (Gráfico 7). As mortes de ciclistas, após queda em 2010, apresentam variação, sendo menores em 2013 e 2015.

Gráfico 7 - Acidentes com ciclistas em São Paulo

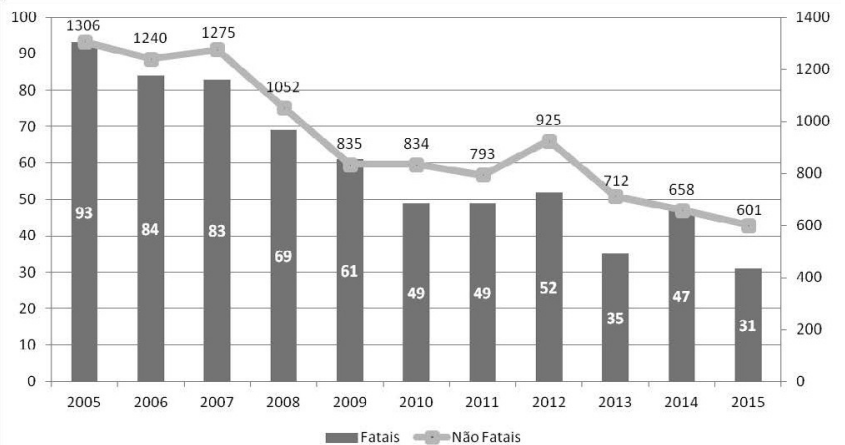

Fonte: Elaboração própria a partir dos dados: COMPANHIA DE ENGENHARIA DE TRÁFEGO. Acidentes de trânsito fatais: relatório anual São Paulo, 2016. Disponível em:<http://www.cetsp. com.br/media/468500/acidentesdetransitofataisanual2015.pdf $>$. Acesso em: 28 nov. 2017.

Apesar de apresentarem resultados bons para a mobilidade por bicicleta, algumas críticas são feitas às políticas. Uma delas se refere à falta de ligação entre as ciclovias do centro e da periferia, principalmente nas pontes e viadutos da cidade (TV CULTURA, 2015; MOBILIDADE ATIVA, 2016; ALESSI, 2015; ZANCHETTA; ITALIANI, 2014); outra diz respeito à falta de bicicletários em terminais de transporte público. (MOBILIZE, 2016). As críticas ao Bike Sampa são principalmente sobre a exigência de cartão de crédito para utilização do sistema. (MOBILIDADE ATIVA, 2016).

\section{ANÁLISE COMPARADA DAS POLÍTICAS}

As três cidades aqui analisadas, apesar de estarem inseridas em contextos urbanos diferentes, possuem trajetórias parecidas em relação a políticas para bicicleta. É a partir dos anos 2000 que as infraestruturas cicloviárias entram na pauta das ações dos poderes municipais. Os mecanismos institucionais utilizados em cada caso para viabilizar essas políticas são um pouco diferentes. Em Nova 
York e São Paulo, as ações estão vinculadas a organizações do governo municipal, responsáveis pelo trânsito e transportes na cidade: o DOT no caso norte americano e a CET no caso paulistano. Na capital mexicana, estão na SMA com acompanhamento da Secretaria de Mobilidade.

Independentemente do órgão gestor, é importante ressaltar que as mudanças partidárias ao longo das gestões podem acarretar mudanças que tendem a priorizar mais ou menos a inserção da bicicleta na matriz modal das cidades. Nova York teve dois prefeitos de partidos opostos desde o início da implementação de ações para fomentar o uso da bicicleta e aparenta certa continuidade nas políticas. Já São Paulo teve 3 prefeitos de partidos distintos e opostos nesse período, com continuidade das políticas entre os dois primeiros, não sendo possível avaliar tal quesito entre a gestão anterior e a atual, que está no primeiro ano de governo. A Cidade do México teve o mesmo partido (PRD) desde o início da implantação de suas políticas cicloviárias, com continuidade das políticas.

Uma questão comum aos três casos são os movimentos sociais que lutam pelos ciclistas. Os de Nova York são da década de 1970, na Cidade do México o ativismo começou a aparecer de modo mais estruturado no final dos anos 1990 e em São Paulo no final dos anos 2000. Nos três casos os grupos acabam agindo com dupla atuação: aumentar o número de ciclistas da cidade, chamando as pessoas a se locomoverem por bicicleta, e cobrar os governos locais para que políticas e planos em favor do ciclismo saiam do papel.

Nesse aspecto, enquanto as administrações municipais de Nova York e São Paulo investiram em ampliar a malha cicloviária, a Cidade do México parece ter optado investir em outras frentes de atuação, como programas educativos e passeios ciclísticos para estímulo ao uso da bicicleta. As três cidades se igualam quando se observa a presença de sistemas de compartilhamento de bicicletas, políticas de traffic calmming e presença de bicicletários públicos, sendo que o volume dessas estruturas varia entre elas (Tabela 2). 
ANALISE COMPARATIVA DE POLÍTICAS PÚBLICAS PARA BICICLETA EM TRÊS GRANDES CIDADES: Nova York, Cidade do México e São Paulo

Tabela 2 - Infraestrutura cicloviária

\begin{tabular}{|c|c|c|c|c|c|}
\hline Cidade & $\begin{array}{c}\text { Km de } \\
\text { ciclovias ou } \\
\text { ciclofaixas }\end{array}$ & $\begin{array}{l}\text { Sistema de Bike } \\
\text { Sharing }\end{array}$ & $\begin{array}{c}\text { Bicicletários } \\
\text { Públicos }\end{array}$ & $\begin{array}{c}\text { Aceita bicicleta no } \\
\text { metrô }\end{array}$ & $\begin{array}{l}\text { Políticas de } \\
\text { traffic } \\
\text { calmming }\end{array}$ \\
\hline Nova York & 1.500 & Citi Bike & $3^{*}$ & $\begin{array}{l}\text { Todos os dias: dia } \\
\text { inteiro }\end{array}$ & Sim \\
\hline $\begin{array}{c}\text { Cidade do } \\
\text { México }\end{array}$ & $\begin{array}{l}170 \\
---\end{array}$ & Ecobici & 28 & $\begin{array}{l}\text { Domingo e feriados: dia } \\
\text { inteiro }\end{array}$ & Sim \\
\hline São Paulo & 468 & $\begin{array}{c}\text { Bike Sampa e Ciclo } \\
\text { Sampa }\end{array}$ & 84 & $\begin{array}{l}\text { Dias úteis: após às } 20 \mathrm{~h} \\
\text { Sábado: após às } 14 \mathrm{~h} \\
\text { Domingo: dia inteiro }\end{array}$ & Sim \\
\hline
\end{tabular}

Fonte: Elaboração própria, a partir de dados: COMPANHIA DE ENGENHARIA DE TRÁFEGO. Bicicleta: um meio de transporte. São Paulo, 2017. Disponível em:<http://www.cetsp.com.br/consultas/bicicleta/bicicleta-um-meio-de-transporte.aspx>. Acesso em: 28 nov. 2017; UNITED STATES. Department of Transportation. Bicyclists. New York City, 2017b. Disponível em:<http:// www.nyc.gov/html/dot/html/bicyclists/bicyclists.shtml>. Acesso em: 28 nov. 2017; e da Secretaria del Medio Ambiente del Distrito Federal (SEDEMA) (MÉXICO, 2012).

Nota: *A cidade de Nova York possui uma lei que obriga prédios comerciais a destinar vagas em seus estacionamentos para bicicletas. O número de bicicletários públicos pode estar subestimando o número real de vagas protegidas.

Buscando captar o impacto das infraestruturas cicloviárias nas três cidades, apresentamos os dados da série histórica de contagens em uma via de cada cidade. O local escolhido para cada uma delas seguiu os seguintes critérios: via de importante ligação entre bairros residenciais e a região central, existência de dados de contagem antes e depois da implantação da ciclovia, proximidade com equipamentos de transporte de alta capacidade. Como pode ser visto na Tabela 3, em relação a Nova York, a ponte Manhattan Bridge, que liga o bairro do Brooklin ao centro econômico da cidade, apresentou um aumento médio de $10 \%$ no volume de ciclista a cada ano. O acesso de ciclistas à ponte se dá desde o ano de 2001, o que sugere que a ampliação da malha cicloviária na cidade ao longo da administração Bloomberg motivou o aumento de ciclistas no acesso a Manhattan. No caso da Cidade do México, a Av. Paseo de La Reforma é uma importante via de transporte, cortando o centro de norte a sul, passando por regiões que concentram empresas, residências, equipamentos públicos e de lazer. Em 2010 foi implantada uma ciclovia que cobre boa parte da extensão da avenida, o que parece crucial para explicar o aumento em 18 vezes do número de ciclistas. No caso paulistano, a Av. Eliseu de Almeida é uma importante via de ligação entre parte da zona oeste da cidade e o metrô Butantã, estação com bicicletário e terminal de ônibus de linhas municipais e intermunicipais. A ci- 
clovia nessa avenida foi implantada em 2014. O volume de ciclistas entre os anos de 2012 e 2016 aumentou em $212 \%$.

Tabela 3 - Contagens

\begin{tabular}{|l|c|c|c|c|c|c|c|c|c|}
\hline \multicolumn{1}{|c|}{ Cidade } & $\mathbf{2 0 0 8}$ & $\mathbf{2 0 0 9}$ & $\mathbf{2 0 1 0}$ & $\mathbf{2 0 1 1}$ & $\mathbf{2 0 1 2}$ & $\mathbf{2 0 1 3}$ & $\mathbf{2 0 1 4}$ & $\mathbf{2 0 1 5}$ & $\mathbf{2 0 1 6}$ \\
\hline $\begin{array}{l}\text { Nova York } \\
\text { Manhattan Bridge* }\end{array}$ & 2.993 & 3.550 & 4.041 & 4.952 & 5.270 & 5.678 & 6.132 & 6.223 & 6.203 \\
\hline $\begin{array}{l}\text { Cidade do México } \\
\text { Av. Paseo de la Reforma** }\end{array}$ & 94 & 106 & 1.914 & 2.709 & 3.636 & 4.339 & - & - & - \\
\hline $\begin{array}{l}\text { São Paulo aulo } \\
\text { Av. Eliseu de Almeida*** }\end{array}$ & - & - & 561 & - & 580 & & 888 & 1.245 & 1.810 \\
\hline
\end{tabular}

Fonte: Elaboração própria a partir de dados da Ciclocidade (ASSOCIAÇÃO DOS CICLISTAS URBANOS DE SẨO PAULO, 2012), DOT (UNITED STATES. Departament of Transportation. Bicycle Counts. New York City, 2017. Disponível em: <http://www.nyc.gov/html/dot/html/bicyclists/ bike-counts.shtml >. Acesso em: 28 nov, 2017) e ITDP (INSTITUTO DE POLÍTICAS PARA EL TRANSPORTE Y EL DESARROLLO, 2014).

Notas: *Contagem automática 24 horas (média por dia).

${ }^{* *}$ Contagem entre as $6 \mathrm{~h}$ e as $22 \mathrm{~h}$.

${ }^{* * *}$ Contagem entre as $6 \mathrm{~h}$ e as $20 \mathrm{~h}$.

Apesar de não existir o histórico completo das contagens nas três vias escolhidas, o que se percebe é que a implantação da ciclovia nesses locais exerce, primeiramente, um boom no volume de ciclistas $^{4}$ e, depois, o crescimento vai se consolidando ao longo dos anos até se estabilizar. O caso nova-iorquino parece estar se estabilizando. Já os dados da Av. Paseo de La Reforma não permitem fazer esta inferência por conta da interrupção na série histórica. Em São Paulo, o número de ciclistas na Av. Eliseu de Almeida aparenta estar em movimento de crescimento.

Ainda que os dados não sejam comparados entre si, pois cada cidade possui uma metodologia de contagem, eles apontam o crescimento de ciclistas nessas vias e exemplificam os possíveis impactos que a implantação de uma ciclovia pode resultar.

\section{CONCLUSÃO}

Apesar das diferenças observadas nas políticas cicloviárias, elas parecem ter influenciado positivamente o número de ciclistas e negativamente o número de mortes e acidentes com ciclistas ${ }^{5}$ nas três cidades. Todas passaram, recentemente, por momentos de intensificação das políticas voltadas para a mobilidade por bicicleta e tiveram algum tipo de continuidade dessas políticas entre gestões municipais diferentes. 
Dentre os instrumentos de política pública utilizados, todas as cidades criaram ou incentivaram a criação de bicicletários, construíram ciclovias e ciclofaixa, reduziram a velocidade dos carros (traffic calming) e incentivaram a intermodalidade com ações como a permissão da entrada com bicicleta no metrô e a implantação de sistemas de compartilhamento de bicicletas.

Ainda que diversas ações venham sendo colocadas em prática, o acompanhamento das políticas não parece ser uma preocupação de mesma dimensão para todas as cidades, já que em alguns casos faltam dados sistemáticos tanto sobre o volume de uso da bicicleta, quanto o aumento ou a redução das infraestruturas disponíveis.

O caráter recente das políticas cicloviárias nas 3 cidades ainda não permite dizer se as alterações partidárias no controle gestão municipal tendem a fortalecer ou enfraquecer o processo iniciado. A bicicleta como meio de transporte parece estar ainda se consolidando nas três cidades analisadas, principalmente quando vista da perspectiva da importância que ela possui dentro do planejamento de transportes de cada uma delas.

O desdobramento do trabalho aqui apresentado resulta, por um lado, em um achado que ressalta a juventude e a eficácia das políticas cicloviárias nas três cidades. Datam, em grande parte, dos anos 2000 e o uso da bicicleta, nas medições existentes, aparece quase sempre em trajetória crescente. Por outro, indica a necessidade de ampliar estudos sobre o uso da bicicleta e sua relação com o poder público municipal em longo prazo. Ademais, seria de extrema importância verificar se os processos de implementação de políticas cicloviárias em outras metrópoles do mundo seguem o mesmo caminho dos três casos abordados, principalmente naquelas em que o interesse do poder público sobre o uso da bicicleta tenha se dado recentemente.

\section{REFERÊNCIAS}

ALESSI, G. Ciclovias não chegam à periferia. El País, São Paulo, 14 set. 2015. Disponível em: <http://brasil.elpais.com/brasil/2015/09/02/ politica/1441203294_570383.html . Acesso em: 24 fev. 2017.

ASSOCIAÇÃO DOS CICLISTAS URBANOS DE SÃO PAULO.

Relatório de contagem de ciclistas - Av. Eliseu de Almeida 2016. São Paulo, 2016. Disponível em: $<$ http://www.ciclocidade.org.br/quem- 
somos/noticias/881-relatorio-de-contagem-de-ciclistas-av-eliseu-dealmeida-2016>. Acesso em: 20 fev. 2017.

BICITEKAS. Balance y lecciones aprendidas (2007-2012): políticas públicas para el ciclismo urbano em la Ciudad de México. Cidade do México, 2013.

BRASIL. Ministério das Cidades. Secretaria Nacional de Transporte e da Mobilidade Urbana. Programa Brasileiro de Mobilidade por Bicicleta. Caderno de referência para elaboração de: Plano de Mobilidade por Bicicleta nas Cidades. Brasília, DF, 2007. (Coleção Bicicleta Brasil, n. 1).

CENTRO BRASILEIRO DE ANÁLISE E PLANEJAMENTO. Contagem de ciclistas no município de São Paulo. São Paulo, 2015. Relatório técnico.

CERVERO, R. et al. Influences of built environments on walking and cycling: lessons from Bogotá. International Journal of Sustainable Transportation, Philadelphia, PA, v. 3, n. 4, p. 203-226, 2009.

CICLOCIDADE. Contagens de ciclistas. São Paulo, 2017. Disponível em: <https://www.ciclocidade.org.br/contagem>. Acesso em: 28 nov. 2017.

COMISIÓN NACIONAL PARA EL USO EFICIENTE DE LA ENERGÍA. Bicicleta - Movilidad y transporte. Ciudad de México, 2014.

COMPANHIA DE ENGENHARIA DE TRÁFEGO.

Acidentes de trânsito fatais: relatório anual. São Paulo, 2016.

Disponível em: $<$ http://www.cetsp.com.br/media/468500/

acidentesdetransitofataisanual2015.pdf > Acesso em: 28 nov. 2017.

. Bicicleta: um meio de transporte. São Paulo, 2017.

Disponível em: $<$ http://www.cetsp.com.br/consultas/bicicleta/bicicletaum-meio-de-transporte.aspx $>$. Acesso em: 28 nov. 2017.

COX, P. Social movement activism, social change and bicycling in the UK. [S. 1.], 2015. Draft paper for panel on "Cycling practices and sustainable mobility transitions" at the $\mathrm{T}^{2} \mathrm{M} / \mathrm{Cosmobilities}$ Joint Conference "The Future of Mobilities: Flows, Transport and Communication" in Santa Maria, Itália.

ECOBICI. Estadísticas. Ciudad de México, 2017. Disponível em: $<$ https://www.ecobici.cdmx.gob.mx/es/estadisticas $>$. Acesso em: 24 fev. 2017. 
ANALISE COMPARATIVA DE POLÍTICAS PÚBLICAS PARA BICICLETA EM TRÊS GRANDES CIDADES: Nova York, Cidade do México e São Paulo

GOODYEAR, S. How the Dutch got their cycle paths. New York: Project for Public Spaces, nov. 2011. Disponível em: $<$ https://www. pps.org/blog/how-the-dutch-got-their-cycle-paths/>. Acesso em: 10 jun. 2016.

INSTITUTO DE POLÍTICAS PARA EL TRANSPORTE Y EL DESARROLlO. Conteo ciclista: 2013. Ciudad de México, 2014. INSTITUTO NACIONAL DE ESTADÍSTICA GEOGRAFÍA E INFORMÁTICA. Accidentes de tránsito terrestre en zonas urbanas y suburbanas. Ciudad de México, 2016. Disponível em: $<$ http://www. inegi.org.mx/est/lista_cubos/consulta.aspx? $\mathrm{p}=\mathrm{adm} \& \mathrm{c}=1>$. Acesso em: 24 fev. 2017.

Encuesta Intersensal 2015. Ciudad de México, 2015.

Encuesta Origen: Destino 2007. Ciudad de México, 2007.

MALATESTA, M. E. B. A bicicleta nas viagens cotidianas do município de São Paulo. 2014. 251 f. Tese (Doutorado) - Faculdade de Arquitetura, Universidade de São Paulo, São Paulo, 2014.

MÉXICO. Gobierno del Distrito Federal. Administración Pública del Distrito Federal. Gaceta Oficial Del Distrito Federal, Ciudad de México, décima segunda época, n. 146, 2002.

Secretaria del Medio Ambiente del Distrito Federal. Estrategia de Movilidad em bicicleta de la Ciudad de México. Ciudad do México, 2012.

Secretaria del Medio Ambiente del Distrito Federal. Movilidad Sustentable. Ciudad do México, 2017.

MIDGLEY, P. Bicycle-sharing Schemes: enhancing sustainable mobility in urban areas. Nova York: Departament of Economic and social affair, 2011. Commission on Sustainable Development, Nine Teenth Session. (Background Paper, n. 8).

The Role of Smart Bike-sharing Systems in Urban Mobility. Jurneys, [S. 1.], v. 2, may 2009.

MOBILIDADE ATIVA. Compromissos com a Mobilidade Ativa. São Paulo, 2016. Disponível em: $<$ http://mobilidadeativa.org.br/consultapublica/>. Acesso em: 24 fev. 2017.

MOBILIZE. Em São Paulo, aumento de ciclistas lota bicicletários. São Paulo, 2016. Disponível em: $<$ http://www.mobilize.org.br/ 
noticias/9476/sao-paulo-precisa-de-mais-bicicletarios.html>. Acesso em: 24 fev. 2017.

PUCHER, J. et al. Walking and cycling to health: a comparative analysis of City, State, and International Data. American Journal Of Public Health, [S. 1.], v. 100, n. 10, p.1986-1992, out. 2010. Disponível em: $<$ http://dx.doi.org/10.2105/ajph.2009.189324>. Acesso em: 24 fev. 2017.

; BUEHLER, R. Walking and Cycling for Healthy Cities. Built Environment, [S. 1.], v. 36, n. 4, p. 391-414, dez. 2010. Disponível em:<http://dx.doi.org/10.2148/benv.36.4.391>. Acesso em: 24 fev. 2017.

; KAMANOFF, C.; SCHIMEK, P. Bicycling renaissance in North America? Recent trends and alternative policies to promote bicycling. Transportation Research Part A, New York, v. 33, n. 7/8, p. 625-654, 1999

SANDOVAL, J. H. L. La importancia de la bicicleta en la movilidad del Distrito Federal. 2012. Dissertação (Mestrado) - Faculdade de Arquitetura, Universidade Nacional Autónoma de México, 2012.

SÃO PAULO. Secretaria de Estado dos Transportes Metropolitanos. Companhia do Metropolitano de São Paulo. Pesquisa Origem e Destino - 2007: síntese das informações - pesquisa domiciliar. São Paulo, 2008.

. Secretaria de Estado dos Transportes Metropolitanos.

Companhia do Metropolitano de São Paulo. Pesquisa de Mobilidade Urbana 2012: síntese das informações - pesquisa domiciliar. São Paulo, 2013.

SHAHEEN, S.; GUZMAN, S.; ZHANG, H. Bikesharing in Europe, the Americas, and Asia. Transportation Research Record: Journal of the Transportation Research Board, [S. 1.], v. 2143, p. 159-167, 2010.

SMETHURST, P. The bicycle: towards a global history. New York: Palgrave Macmillan, 2015.

TUCKEL, P.; MILCZARSKI, W. Bike Lanes or Blocked Lanes? An Observational Study of Vehicular Obstructions of Bike Lanes in Manhattan. New York: Hunter College, Departament of Sociology an Urban Plannig, 2009. 
ANALISE COMPARATIVA DE POLÍtiCAS PÚBLICAS PARA BICICLETA EM TRÊS

GRANDES CIDADES: Nova York, Cidade do México e São Paulo

TV CULTURA. Debate sobre ciclovia. Programa Jornalismo TV Cultura, São Paulo, 29 jun. 2015. Disponível em: $<$ https://www. youtube.com/watch?v=5T5K1vNmCHE $>$. Acesso em: 24 fev. 2017.

UNITED STATES. Departament of Transportation. Plan NYC: a greener, greater New York. New York, 2007.

Bicycle Counts. New York City, 2017a. Disponível em: $<$ http://www.nyc.gov/html/dot/html/bicyclists/bike-counts.shtml $>$. Acesso em: 28 nov, 2017.

. Bicyclists. New York City, 2017b. Disponível em:

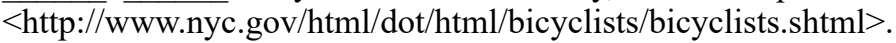
Acesso em: 28 nov. 2017.

Cycling in the New York City: Cycling Trends in NYC. Nova York, 2017c.

New York City Mobility Report. Nova York, 2016.

Vision Zero Data Feeds. New York, 2017d.

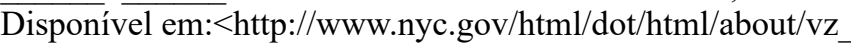
datafeeds.shtml\#crash>. Acesso em: 20 fev. 2017.

WANG, R.; LIU, C. Bicycle-Transit Integration in the United States, 2001-2009. Journal of Public Transportation, Tampa, v. 16, n. 3, p. 95-119, 2013.

ZANCHETTA, D.; ITALIANI, R. Faltam ciclovias onde mais se usam bicicletas em São Paulo. Estadão, São Paulo, 14 set. 2014. Disponível em: $<$ http://sao-paulo.estadao.com.br/noticias/geral,faltam-cicloviasonde-mais-se-usam-bicicletas-em-sao-paulo-imp-,1559805>. Acesso em: 24 fev. 2017.

\section{Notas}

Locais onde a velocidade máxima dos veículos automotores é reduzida para 20 a $40 \mathrm{~km} / \mathrm{h}$.

2 O dado mais recente disponível só existe para pessoas acima de 12 anos e empregadas. No entanto, estas pessoas representam a maior parte das viagens, servindo de estimativa para o resto da população. (INSTITUTO NACIONAL DE ESTADISTICA GEOGRAFIA E INFORMÁTICA, 2007).

3 Em São Paulo, em 12 horas de contagem, o CEBRAP aferiu, em 2015, 1.852 ciclistas na ciclovia da Av. Faria Lima, uma das mais utilizadas da cidade.

4 A ponte nova-iorquina já possuía estrutura desde o ano de 2001 que foi, aos poucos, sendo adequada ao longo do tempo. No ano de inauguração apresentou um aumento de $271 \%$ no volume de ciclistas, passando de $207 \mathrm{em} 2001$ para $767 \mathrm{em} 2002$.

5 A Cidade do México apresenta uma queda nos acidentes com ciclistas desde 2012, apesar das mortes com ciclistas terem uma trajetória menos clara nesse período. 
